\title{
Climate Change and Sustainable Development: The Appropriate Technology Concept
}

\author{
Sunday O. Amiolemen ${ }^{1}$, Idowu O. Ologeh ${ }^{1} \&$ John A. Ogidan ${ }^{1}$ \\ ${ }^{1}$ National Centre for Technology Management, 9 Kofo Abayomi Victoria Island, Lagos, Nigeria \\ Correspondence: Sunday O. Amiolemen, National Centre for Technology Management, Southwest Office, 9 \\ Kofo Abayomi Street, Victoria Island, Lagos, Nigeria. Tel: 703-387-0090. E-mail: samiolemen@gmail.com
}

Received: March 9, 2012 Accepted: April 13, 2012 Online Published: May 1, 2012

doi:10.5539/jsd.v5n5p50

URL: http://dx.doi.org/10.5539/jsd.v5n5p50

\begin{abstract}
The global ecosystem which includes the earth's atmosphere is daily impacted upon by humans deliberately or inadvertently, as a result of agricultural activities, industrialization and in the daily pursuit of other economic gains. In the course of these processes, the earth's atmosphere and the environment are impacted upon thus, leading to climate change, global warming and loss of biodiversity. This paper promotes sustainable environment and development through the concept of appropriate technology. The paper reasoned that third-world countries may lack the mainstream technology for combating environmental pollution; as such alternative technology that suits the culture and value system should be adopted as preventive and control measures. Appropriate Technology offers the best solution in achieving industrial and agricultural development in developing countries void of environmental distress and pollution. The paper concludes that Appropriate Technology provides a pathway to industrial and economic development, while taking environmental health into consideration. In light of this, the paper finally relates the concept of appropriate technology to soil fertility.
\end{abstract}

Keywords: appropriate technology, biodiversity, climate change, environmental health, sustainable development

\section{Introduction}

Humans have greatly influenced the global ecosystem as a result of globalization and industrialization. This influence has considerably increased in recent times, as agricultural societies have been injudiciously transformed into societies based on industry and trade. As global economy is increasing, so is the use of energy. The concentration of $\mathrm{CO}_{2}$ and other compounds of carbon in the atmosphere are also increasing at an exponential rate. In many regions, increase in the concentrations of phosphate and nitrogen in soils and water has resulted into loss of biodiversity while the indiscriminate exploitation of natural resources has led to soil erosion and other environmental degradation. Meadows et al. (1992) observed that industrial output and population will keep on growing until a combination of environmental and resource constraints are met. As a result, fatal consequences in respect to high mortality, shortage of food and outburst of epidemic may occur. This is more evident in developing countries where the practice of shifting cultivation or bush fallow needed for the regeneration of soil nutrients is becoming impossible due to unavailability of land as a result of urbanization and industrialization. However, application of green technology could help sustain the environment, protect biodiversity and global climate through the incorporation of plant species which use environmental resources efficiently for ecological stability and soil nutrients build-up.

Industrialization and globalization affect the environment in different ways and through various channels, most especially through the indiscriminate use of non-green energy and waste disposals. Considering the large scale environmental pollution, ozone depletion, global warming and loss of biodiversity; it is important to use appropriate technology in forestalling these environmental ills.

Sustainability is an important concept in this age and time, more importantly in the awakening era of globalization and sustainable development. The Brundtland Commission considers sustainable development as development that meets the needs of the present without compromising the ability of future generations to meet their own needs. In this context, sustainability is defined as a holistic development that meets the needs of present generations without jeopardizing the ability of future generations to meet their own needs. This is achievable through the use of eco-efficient solutions, by developing new technologies, employing life cycle perspectives in resource and product stewardship, and of course positively addressing biological diversity and ecosystem dynamics. 
Considering the immeasurable negative impacts of humans on the environment, there is an urgent need to appreciate and adopt an appropriate technology in exploring and exploiting resources needed for economic and industrial development. This is where the concept of sustainability comes in handy when correctly instituted and applied in meeting socio-economic and technological needs of a society. In most developing countries the concept of sustainable development has received little or no attention, with lack of commitment, political will and inconsistent policies in adopting and enforcing the use of technologies that are environment friendly. It is important to promote sustainable technology and environment policies that favor the enforcement, adoption and use of green/ appropriate technology for a sustainable environment. Technology itself should also be used as a tool in pollution reduction and control. Appropriate Technology (AT) needs to be adopted right from resource extraction, processing, packaging, post- production to the generation, disposal and recycling of wastes. It could be rightly said that a sustainable environment is possible, if appropriate technology is adopted and enforced in all sectors of the economy.

\section{Literature Review}

\subsection{Appropriate Technology and Sustainable Development}

Appropriate technology is technology that is sustainable-biased, designed with special consideration to the natural environment, and the socio-cultural, political and economic environment of the Society. Appropriate technology is always easy to maintain and most importantly environment friendly; its low cost, low usage of fossil fuels and use of locally available resources endear it as a veritable tool for sustainable development. The term Appropriate Technology, has been erroneously stereotyped as a cheap and elementary type of technology befitting of developing countries only. In reality Appropriate Technology is a global brand. This type of technology results in less negative impact on the environment; it is cost effective, durable and functional. In perspective, sustainable development in its true sense is achievable, most especially in developing countries if the concept of Appropriate Technology is wholly practiced. Though, sustainable development is a global issue, however, it is of note that developing countries lack the mainstream technology in combating environmental problems and their attendant consequences. As such, Appropriate Technology may be the keystone to minimizing pollution and at the same time aids the economy. In Nigeria, for example Appropriate Technology can be utilized in all sectors of the economy from agriculture to industrial production. The generation and emissions of greenhouse gases can be minimally reduced through the application of Appropriate Technology which promotes energy and materials efficiency. In addition, Appropriate Technology to a large extent also provides a pathway to technology independence to third-world countries, as it gives rooms for innovation and invention using readily available resources in meeting their needs. The paradigm of Appropriate Technology has been successfully used in Brazil, Malaysia, Singapore, and India in providing a viable economy as leading producers of essential and luxury goods to other third-world countries.

\subsection{The Nature of Appropriate Technology}

Appropriate Technology may be categorized into Appropriate Hard Technology (AHT) and Appropriate Soft Technology (AST). Albertson \& Faulkner (1998) defines Appropriate Hard Technology as engineering techniques, physical structures, and machinery that meet a need defined by a community, and utilize the material at hand or readily available. This can be built, operated and maintained by the local people with very limited outside assistance (e.g., technical, material, or financial). It is usually related to an economic goal. On the other hand, Appropriate Soft Technology according to Albertson \& Faulkner (1998) is considered as technology that deals with the social structures, human interactive processes, and motivation techniques. In other words the structure and process for social participation and action by individuals and groups in analyzing situations, making choices and engaging in choice-implementing behaviors which bring about change.

\subsection{Appropriate Technology as a Veritable Tool for Sustainable Development}

Sustainable development in third-world countries will remain elusive, until an alternative technology that suits their climes, cultures and economies is recognized and adopted. A technology that depends less on external economy system, but that can easily be built, operated and maintained locally in meeting the needs of the society. In achieving this, it is important to emphasize that developing countries appreciate Appropriate Soft Technology in their quest for technological breakthrough and economic development. It is important to point out that "technology" itself does not bring out product without the injection and infusion of soft technologies, such as innovations, ideas and strategic designs, and management policies. Appropriate Soft Technology, is vital in determining the required technology that can be used in meeting specific societal needs, while making use of local resources at little or no cost without polluting the environment and jeopardizing its use. The failure to identify and fill the gap between Appropriate Soft Technology and Appropriate Hard Technology may be responsible for the dwindling and 
dwarfing of third-world economies. Third-world countries have failed to understand that sustainability is synonymous to affluence and development. In the words of Schumacher, health, beauty and permanence are what Appropriate Technology promotes and that is what sustainability is all about. Figure 1 is a conceptual model of appropriate technology for sustainable development in developing countries. The model shows the pathway to environmental sustainability, resource and human capacity development, technology culture and social development.

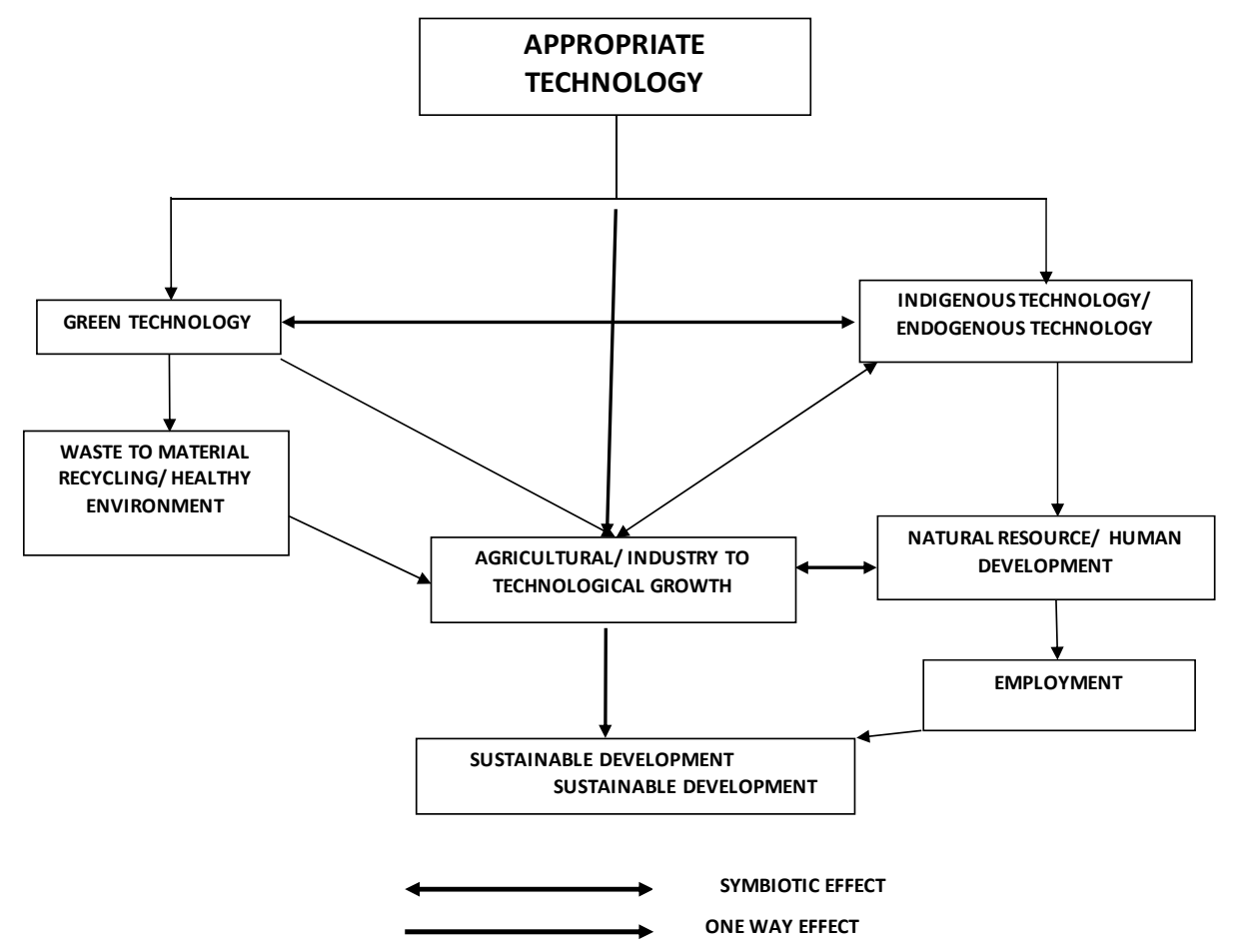

Figure1. Appropriate technology model for sustainable development (Amiolemen, 2012)

Sustainable development is not just a concept but a situation which requires economic efficiency, social equity, human security and ecological stability. Figure 1 clearly depicts how appropriate technology can lead to sustainable development. It brings into focus the application of indigenous technology for industrial growth, within the boundary of environmental health and resource threshold. This could result into high employments and job creations, considering the fact that indigenous technology demands high labor; which itself is an advantage considering the high population of developing countries and the attendant unemployment. Such job creations and employment would ultimately promote social and human security; and of course an enabling environment for economic growth and industrial development. The adoption of fallow management technique that is eco-efficient and ecosystem friendly, which requires local resources and indigenous knowledge in its implementation is a good example of appropriate technology. The adoption of appropriate technology concept in fallow management techniques can reduce minimally the impacts or consequences of climate change on soil habitat and agricultural productivity. In this light, appropriate technology manages available resources such as labour, capital, land and other natural resources for agricultural and environmental sustainability. The adoption of Chromolaena odorata (Siam weed) in fallow management techniques provides a sustainable way in protecting soil habitat and building up nutrients in cultivated farmlands. Below is an application of appropriate technology in restoring soil fertility.

\section{Application of Appropriate Technology in Soil Fertility}

Abandoned farmlands invaded with Chromolaena odorata (Siam weed) of 6 months, 12 months and soils of natural vegetation were identified and selected for study. The study area is the hinterland region of Moniya, located in the southwestern city of Ibadan, Nigeria. A plot size of 20 x 20 metres under the Chromolaena cover and mature forest was gridded for soil samples collection. Ten soil samples were randomly collected from a depth of $0-15 \mathrm{~cm}$ in each plot. A total of thirty soil samples were collected and analysed to determine total 
nitrogen and organic matter content. It was observed that soil under a six month Chromolaena fallow is rich in nitrogen and organic matter content with a slight difference from soils of undisturbed natural vegetation. The implication is that rather than waiting for a long duration of bush fallow which is not viable for rapid crop production as a result of non-availability of lands for shifting cultivation; a 6 month Chromolaena fallow is enough to restore the soil of the farmland to its natural state for all year round cultivation. Table1shows soil organic matter and total nitrogen content under Chromolaena fallows and soils of natural vegetation.

Table 1. Total nitrogen and Soil organic matter contents

\begin{tabular}{lll}
\hline & Nitrogen $(\%)^{*}$ & Organic matter (\%)* \\
\hline 6months Chromolaena fallow & $0.187 \pm 0.01$ & $2.89 \pm 0.15$ \\
lyear Chromolaena fallow & $0.191 \pm 0.01$ & $2.92 \pm 0.17$ \\
Undisturbed natural vegetation & $0.204 \pm 0.05$ & $3.14 \pm 0.21$
\end{tabular}

*Values are means and standard errors.

\section{Conclusion}

Third-world countries need to adopt, appreciate and promote technology philosophies that are people oriented, cost effective and environment friendly. In Appropriate Technology lies the answer to industrial development and economic growth in developing countries; it brings into focus the need to be self-dependent, innovative and inventive without being wasteful. Appropriate Technology does not only affect materials or substances but of course ideologies, values and economic systems of a society for about-face development. The incorporation of plant species in fallow management technique is an appropriate technology that will replenish soil nutrients or can restore the soil status to its natural composition before tillage. Chromolaena (Siam weed) is a natural resource and invasive weed that is abundant in sub-Saharan Africa; it does not require high technology to increase soil fertility. Unlike other soil fertility practices such as fertilizer application and bush burning for potash generation which poses great threat to human, biodiversity and environment; Chromolaena is environment friendly and provides an environment that is conducive for soil microbes and faunas that can facilitate organic matter decomposition, nitrogen fixation and their consequent release to the soil pool. It also helps in the purification of the atmosphere through the absorption of carbon and the release of oxygen into the atmosphere thus reducing global warming throughout the period of fallow. Developing country needs to look inwards to adopt and develop appropriate technology required for self sufficiency and sustainable development. Indigenous and endogenous technology development should be encouraged at schools, from basic to tertiary level for sustainable economic growth and industrial development.

\section{References}

Amiolemen, S. O. (2006). Assessment of Soil Properties Under Chromolaena odorata (L) (Siam Weed) Fallow. Unpublished MSc thesis, University of Ibadan, Ibadan.

Brundtland, H. (1987). Our common future: World Commission on Environment and Development. Oxford University Press.

Faulkner, A. O., \& Albertson, M. L. (1998). Tandem Use of Hard and Soft Technology - An Evolving Model for Third World Village Development. International Journal of Applied Engineering Education, 2(2), 127-137.

Meadows D. H., Meadows D. L., \& Randers, J. (1992). Beyond the Limits: global collapse or a sustainable future. Earthscan Publications.

Schumacher, E. F. (1987). Small Is Beautiful: Economics as If People Mattered. Hartley and Marks publishers.

Ministry of Environment of the Federal Republic of Nigeria. (2003). Nigeria's Initial National Communication under the United Nations Framework Convention on Climate Change. Retrieved April 12, 2011, from http://unfecc.int/resource/docs/natc/nignc1.pdf 